\title{
The Effect of the MJO on the North American Monsoon*
}

\author{
David J. Lorenz and Dennis L. Hartmann \\ Department of Atmospheric Science, University of Washington, Seattle, Washington
}

(Manuscript received 9 July 2004, in final form 1 September 2005)

\begin{abstract}
The effect of the Madden-Julian oscillation (MJO) in the eastern Pacific on the North American monsoon is documented using NCEP-NCAR reanalysis and daily mean precipitation data from 1958 to 2003. It is found that positive zonal wind anomalies in the eastern tropical Pacific lead to above-normal precipitation in northwest Mexico and Arizona from several days to over a week later. This connection between the tropical Pacific and monsoon precipitation appears to be limited to regions influenced by moisture surges from the Gulf of California as a similar connection does not exist for New Mexico precipitation. The evidence suggests that the MJO might affect monsoon precipitation by modulating the strength of low-level easterly waves off the coast of Mexico, which in turn triggers the development of a gulf surge.
\end{abstract}

\section{Introduction}

The North American monsoon (NAM) is a climate phenomenon in the southwest United States and northwest Mexico that typically begins in June and lasts until September. It is associated with a dramatic increase in precipitation over what is normally an arid region of North America (Douglas et al. 1993; Adams and Comrie 1997). This study seeks to better understand processes that control intraseasonal variability of monsoon precipitation. In particular it focuses on the role of the Madden-Julian oscillation (MJO; Madden and Julian 1971, 1994) in modulating precipitation in the NAM. Previous studies on the effect of MJO on North American summer precipitation have emphasized the strong MJO signal in southern Mexico (Higgins and Shi 2001). This study emphasizes the effect of the MJO on precipitation in the monsoon region of Arizona, New Mexico, and northwest Mexico.

Section 2 describes the data and the basic analysis

\footnotetext{
* National Oceanic and Atmospheric Administration Contribution Number 1114.

Corresponding author address: David J. Lorenz, Center for Climatic Research, Institute for Environmental Studies, University of Wisconsin-Madison, 1225 West Dayton St., Madison, WI 53706-1695.

E-mail: dlorenz@wisc.edu
}

methods. Section 3 begins by demonstrating the connection between the MJO and monsoon precipitation, and continues by describing in more detail the time evolution of the wind and precipitation anomalies associated with this connection. The study also suggests possible dynamical mechanisms to explain the observed effect of the MJO on monsoon precipitation.

\section{Data and analysis}

The wind and geopotential height data come from the National Centers for Environmental PredictionNational Center for Atmospheric Research (NCEPNCAR) reanalysis (Kalnay et al. 1996) on a $2.5^{\circ} \times 2.5^{\circ}$ latitude-longitude grid. The 24-h-mean precipitation data come from U.S. and Mexico station data interpolated to a $1^{\circ} \times 1^{\circ}$ latitude-longitude grid using a modified Cressman (1959) scheme (Glahn et al. 1985; Charba et al. 1992). The precipitation dataset is available from the Climate Prediction Center (CPC) Web site (http://www.cpc.ncep.noaa.gov/products/precip/ realtime/retro.shtml). The U.S. portion of the analysis was based on the CPC unified precipitation dataset (Higgins et al. 2000), and the Mexico portion was based on daily station data from about 300 gauge stations prior to the 1990s and about 600 gauge stations afterward. The quality of the precipitation data is not as good over the Mexico portion of the domain; therefore the U.S. portion of the domain is emphasized for the 
TABLE 1 . The starting and ending dates of the monsoon season.

\begin{tabular}{lcccc}
\hline \hline & Daily & Triad & Pentad & Weekly \\
\hline Start of season & 28 June & 28 June & 29 June & 1 July \\
End of season & 1 September & 1 September & 1 September & 1 September \\
\hline
\end{tabular}

indices of monsoon rainfall. Nevertheless, the Mexico portion of the data is included in the analysis and figures because it appears to be broadly consistent with the data north of the international border. Daily NCEP-NCAR reanalysis data at 1200 UTC is used, which is early morning local time at the start of the 24-h-mean precipitation data.

The analysis is performed on data from 1958 to 2003 during the North American monsoon season (late June to early September). For some of the results, the daily data are averaged in time into 3-day-mean (triad), 5-day-mean (pentad), and weekly mean data. The precise season varies with the amount of time averaging such that the season length is a multiple of 3,5 , or 7 (see Table 1). Different time-averaging intervals were used to best present the results of this study: daily and triad data give the best time resolution in order to clearly show the evolution of events in time, while pentad and weekly data improve the signal to noise ratio. The basic results and conclusions of this study are evident regardless of the amount of time averaging. The correlations observed in this study are strongest when the analysis is confined to the peak of the monsoon season rather than including a larger portion of the months of either June or September.

The anomaly data are calculated by removing the mean seasonal cycle, which is a smoothed version of the 46-yr climatology. The climatology is smoothed with a 1-2-1 time filter. The 1-2-1 filter is applied once for the weekly and pentad data and is applied five times for the triad and daily data. The results are not sensitive to the amount of smoothing. After removing the annual cycle, the seasonal-mean anomaly is subtracted from the data in order to remove the interannual variability.

Most of the results are calculated using linear regression analysis rather than compositing analysis. The same general patterns and conclusions were found using both analysis techniques. We choose regression analysis because the results are smoother and the technique is more objective. For the time-lagged regression analysis, data outside of the seasons specified in Table 1 are used. For example, when regressing the wind on a time series with a time lag of 3 days, wind data from 4 September are used even though the season technically ends on 1 September. Statistical significance is deter- mined using a two-sided $t$ test with a significance level of $95 \%$.

\section{Results}

\section{a. Definition of precipitation indices}

To study the effect of MJO on the monsoon, precipitation indices are calculated, which are the average precipitation over a localized region at a given time. The three representative regions that summarize the connection between the MJO and the NAM are called the southern Arizona region (SAZ), the southwest New Mexico region (SWNM), and the northwest Mexico region (NWMEX; Fig. 1). The correlation between the indices for weekly mean data is also shown in Fig. 1.

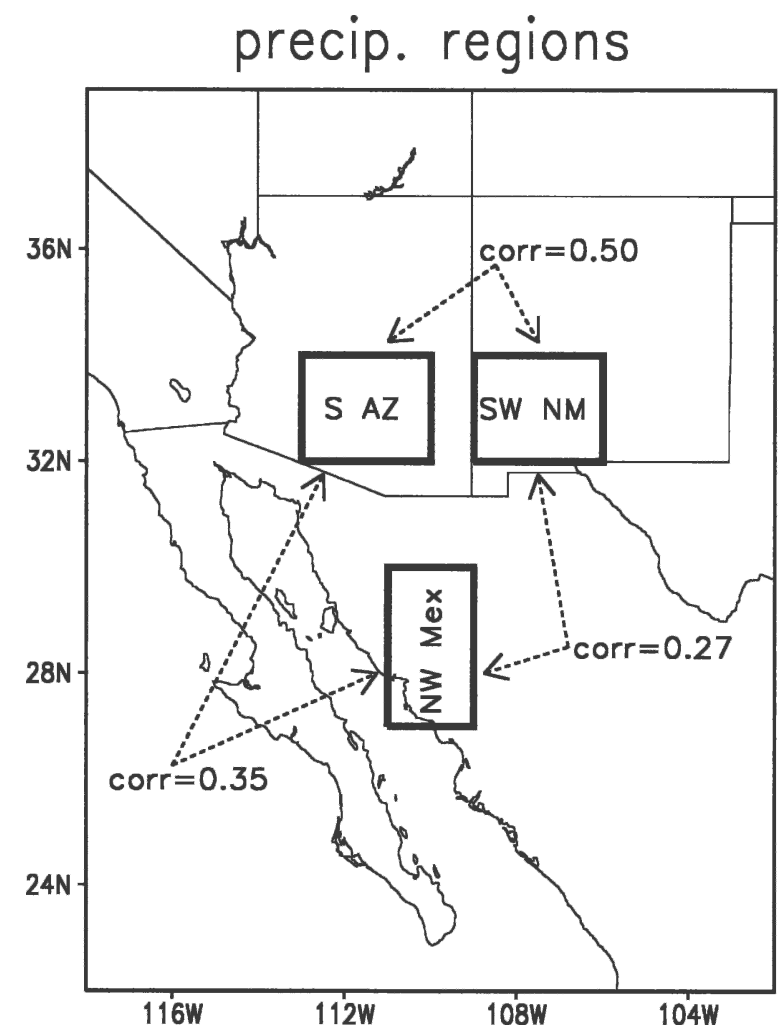

FIG. 1. The three regions that define the three precipitation indices are highlighted in thick rectangles. The names of the regions are included as well as the correlation of precipitation between the regions for weekly mean data. 
TABLE 2. Boundaries of the precipitation regions used to define the three precipitation indices.

\begin{tabular}{lccc}
\hline \hline & SAZ & SWNM & NWMEX \\
\hline Longitude range & $110^{\circ}-113^{\circ} \mathrm{W}$ & $106^{\circ}-109^{\circ} \mathrm{W}$ & $109^{\circ}-111^{\circ} \mathrm{W}$ \\
Latitude range & $32^{\circ}-34^{\circ} \mathrm{N}$ & $32^{\circ}-34^{\circ} \mathrm{N}$ & $27^{\circ}-30^{\circ} \mathrm{N}$ \\
\hline
\end{tabular}

Note that the correlations between adjacent regions are quite small even for weekly mean data.

The precise boundaries of the three regions are given in Table 2. Many different boundaries for the precipitation regions were explored, and it was found that the regions reported here provide a good summary of the types of behavior observed. Also, because the quality of the data is better in the U.S. portion of the domain compared to the Mexico portion, the United States is emphasized in the choice of precipitation regions.

The lag correlation summarizes the relationship between the precipitation regions in time (Fig. 2). The lag-correlation between the SAZ and SWNM indices implies that the covarying portion of the precipitation in these regions tends to occur on the same day, although the correlation drops off less rapidly in time when SAZ leads SWNM. Figure $2 b$ is clearly very different than Fig. 2a and indicates that precipitation in NWMEX tends to lead SAZ by about two days. This time lag might be a signature of moisture surges from the Gulf of California that tend to reach NWMEX before SAZ, although two days seems somewhat slow for this explanation. A similar but not as pronounced time lag is also evident between NWMEX and SWNM.

\section{b. Connection to Tropics}

To investigate the relationship between NAM precipitation and the large-scale circulation, the $850-\mathrm{mb}$ zonal wind is regressed on the three precipitation indices defined above (Fig. 3). Note that the precipitation indices lag the zonal wind so that Fig. 3 shows the wind anomalies that precede the rain events. This study emphasizes the wind anomalies in the Tropics, which are a signature of the MJO.

Looking at Fig. 3, one sees that statistically significant zonal wind anomalies in the East Pacific at $12.5^{\circ} \mathrm{N}$ precede precipitation in SAZ and NWMEX but not in SWNM. As shown in previous studies (Maloney and Hartmann 1998, 2001), the 850-mb zonal wind in this region is directly related to the MJO. An index of 850$\mathrm{mb}$ zonal wind provides further evidence suggesting that this East Pacific wind variability is directly related to the MJO. This East Pacific wind index is the average zonal wind anomaly over the box in the East Pacific
Lag Correlation

a) S AZ \& SW NM

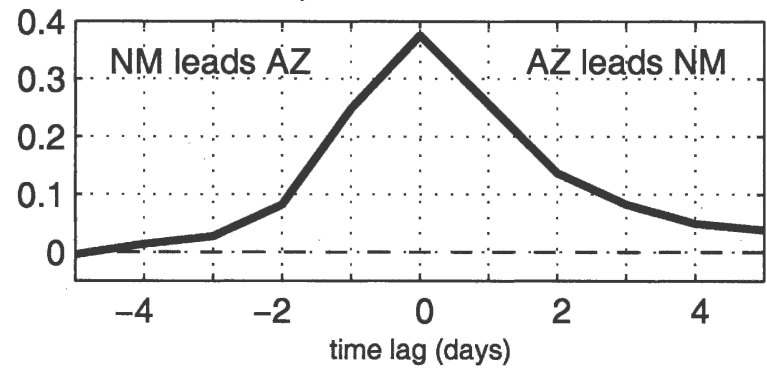

b) NW Mex \& S AZ

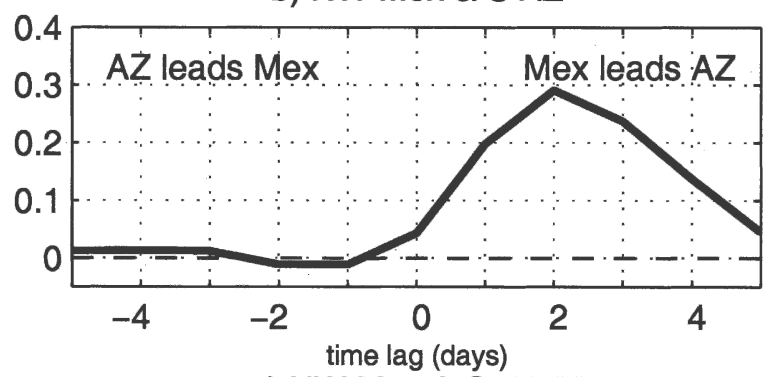

c) NW Mex \& SW NM

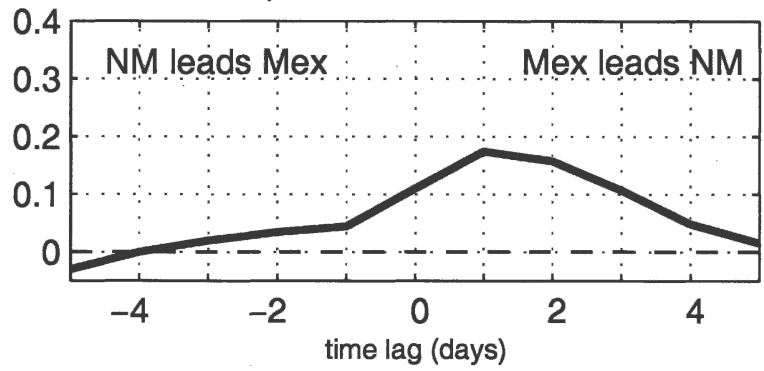

FIG. 2. The lag correlation between the time series of precipitation (daily, 1958-2003) in the three regions: SAZ, SWNM, and NWMEX.

(Fig. 3d). A second index is also calculated in the West Pacific where negative anomalies are evident in Fig. 3a. The power spectra over the entire warm season (MaySeptember) show a statistically significant peak at a period of about 50 days for both the East and West Pacific indices (Fig. 4a). Moreover, the coherence squared becomes quite large at periods of 38 and 50 days demonstrating that the variability in these two widely separated regions reflects the dynamics of a global-scale mode (Fig. 4b). The preferred period and global-scale nature of the variability in the tropical Pacific implies that the variability is directly related to the MJO. The fact that monsoon precipitation is most correlated with the East Pacific portion of the global anomalies suggests that the global-scale MJO and the NAM region are linked through processes in the East Pacific. 
$u$ wind at $850 \mathrm{mb}$ regressed on precip. index (wind leads precip. by 2 pentads)

a) $S A Z$

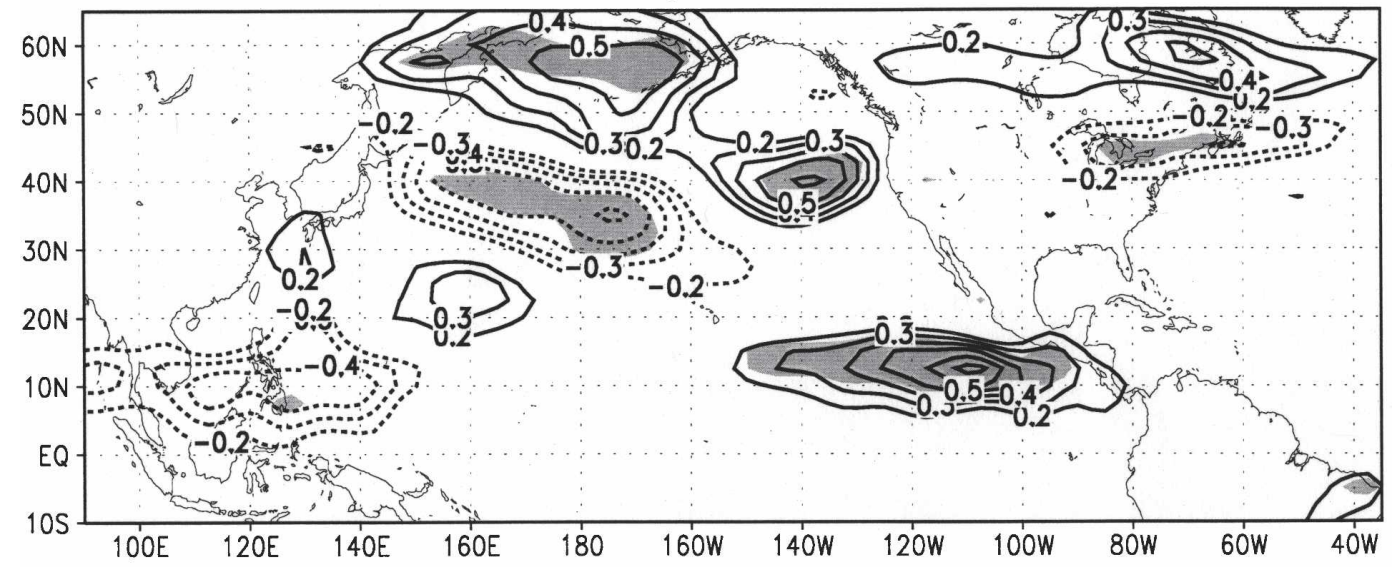

b) SW NM

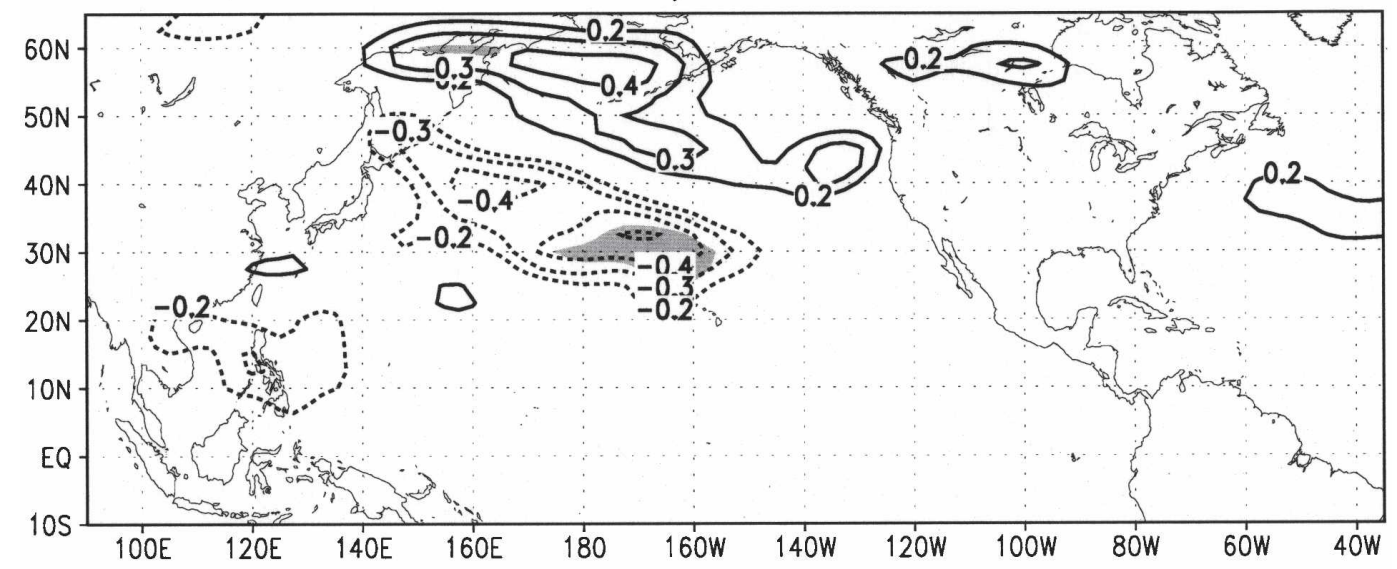

c) NW Mex

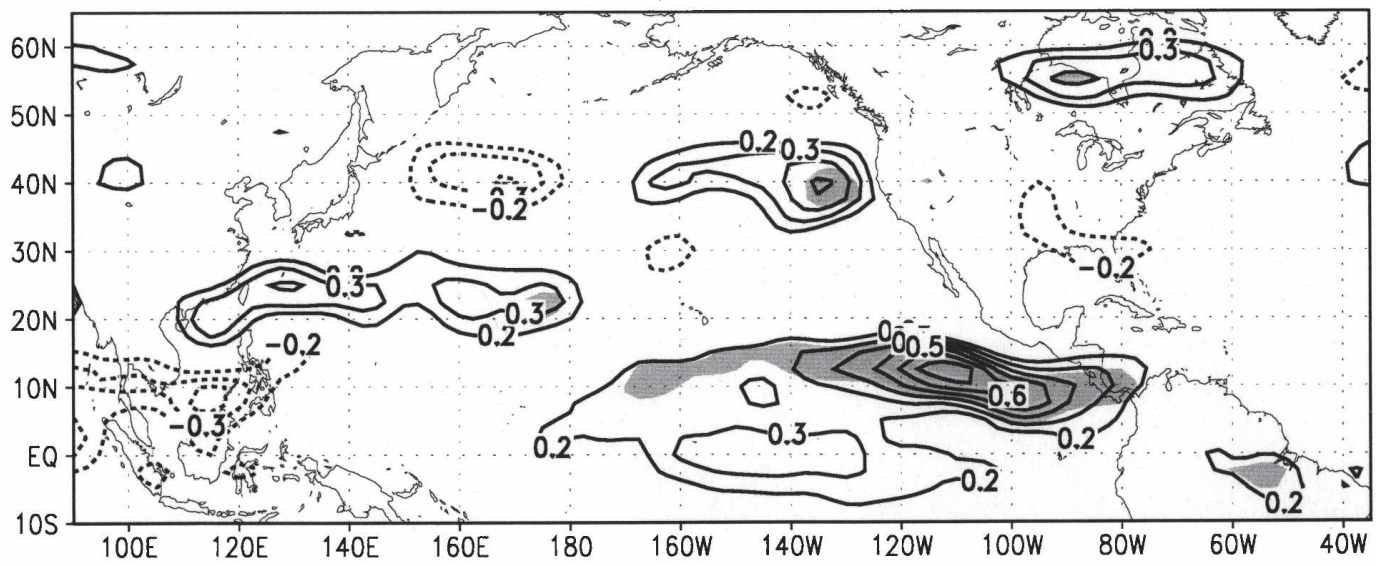

d) wind index regions

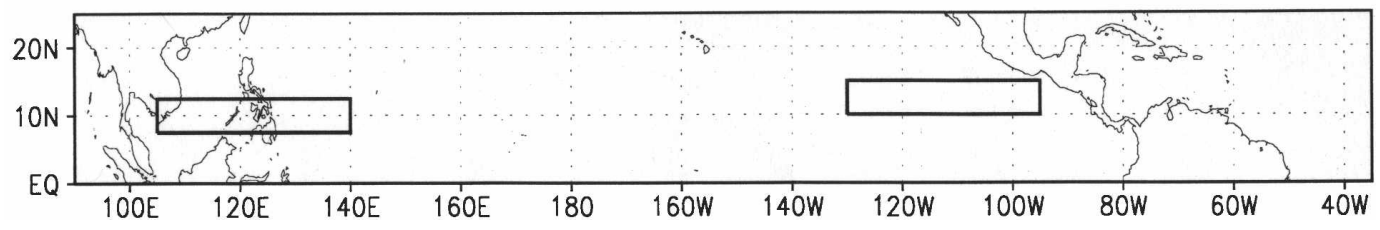


a) power spectrum for $850 \mathrm{mb} u$ wind
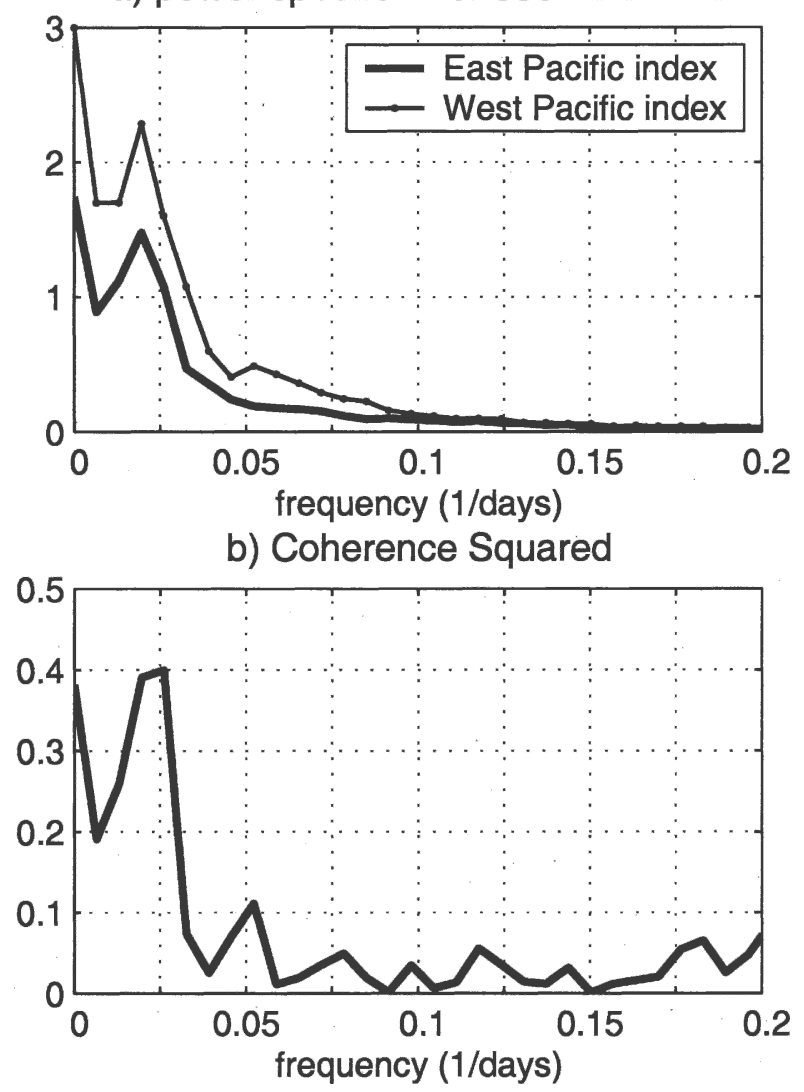

FIG. 4. (a) The power spectra of the $850-\mathrm{mb}$ zonal wind time series in the West and East Pacific. The spectra were computed using data from the entire warm season (1 May 1 to 30 September) so that low frequencies can be resolved. In addition, the seasonal mean has not been removed so that one can compare interannual variability (frequency $=0$ ) with intraseasonal variability. (b) Coherence squared between the West and East Pacific time series.

The reasons for the MJO link to SAZ precipitation but not SWNM precipitation become clearer when one looks at the $850-\mathrm{mb}$ winds and heights at the time of the precipitation events (Fig. 5). ${ }^{1}$ Rainfall in SAZ tends to be associated with a strong surge of southerly wind

\footnotetext{
${ }^{1}$ Note that although SWNM does not have a significant zonal wind anomaly in the tropical East Pacific, both SAZ and SWNM share a similar extratropical north/south zonal wind dipole in the North Pacific (Figs. 3a,b).
}

from the Gulf of California, while rainfall in SWNM tends to be associated with easterly, upslope winds from the Great Plains. Thus, it appears that the MJO influences NAM rainfall through its effect on surges of moisture from the Gulf of California ("gulf surges"). Because most of SWNM lies on the eastern side of the continental divide, the effect of gulf surges on NM rainfall is much less than AZ. A possible mechanism connecting the MJO and gulf surges will be explored below, but first the time evolution of the East Pacific zonal wind and NAM precipitation will be looked at in more detail.

\section{c. Time evolution}

The time evolution of the tropical zonal wind associated with NAM precipitation is summarized by regressing the zonal wind along $12.5^{\circ} \mathrm{N}$ with the precipitation indices for different time lags (Fig. 6). As seen previously in Fig. 3, statistically significant zonal wind anomalies in the East Pacific precede NAM precipitation. In addition to this feature, Fig. 6 also shows that negative wind anomalies follow the precipitation events. These negative anomalies exist because the MJO is a quasi-periodic phenomenon so that negative anomalies tend to follow positive anomalies. Also note the somewhat out of phase anomalies in the West Pacific that accompany the East Pacific anomalies. Although these anomalies barely pass the significance level for the SAZ case, we believe these anomalies indicate a real, physical connection because nearly out of phase West Pacific anomalies accompany MJO anomalies in the East Pacific (Maloney and Hartmann 1998). Also note that the wind anomalies associated with NWMEX are shifted in time by roughly one triad (3day-mean data) compared to SAZ, which is consistent with the idea that the MJO affects the monsoon through gulf surges-the gulf surges reach NWMEX before SAZ. The $12.5^{\circ} \mathrm{N}$ zonal wind plot for SWNM precipitation has weak statistically insignificant anomalies (not shown).

To show the time evolution of the precipitation associated with East Pacific wind anomalies, one can correlate the East Pacific zonal wind index defined previously (Fig. 3d) with the precipitation anomalies for different time lags (Fig. 7). At the time of maximum zonal wind anomalies $(\mathrm{lag}=0)$, the precipitation is strongest

$\leftarrow$

FIG. 3. 850-mb zonal wind anomalies $\left(\mathrm{m} \mathrm{s}^{-1}\right)$ regressed on each of the precipitation indices (pentad data). The zonal wind anomalies lead the precipitation by two pentads. The statistically significant features are shaded (95\%): (a) SAZ, (b) SWNM, and (c) NWMEX. (d) The two rectangles highlight the regions used to define the West Pacific and East Pacific zonal wind indices. 
$850 \mathrm{mb}$ wind \& heights regressed on precip index
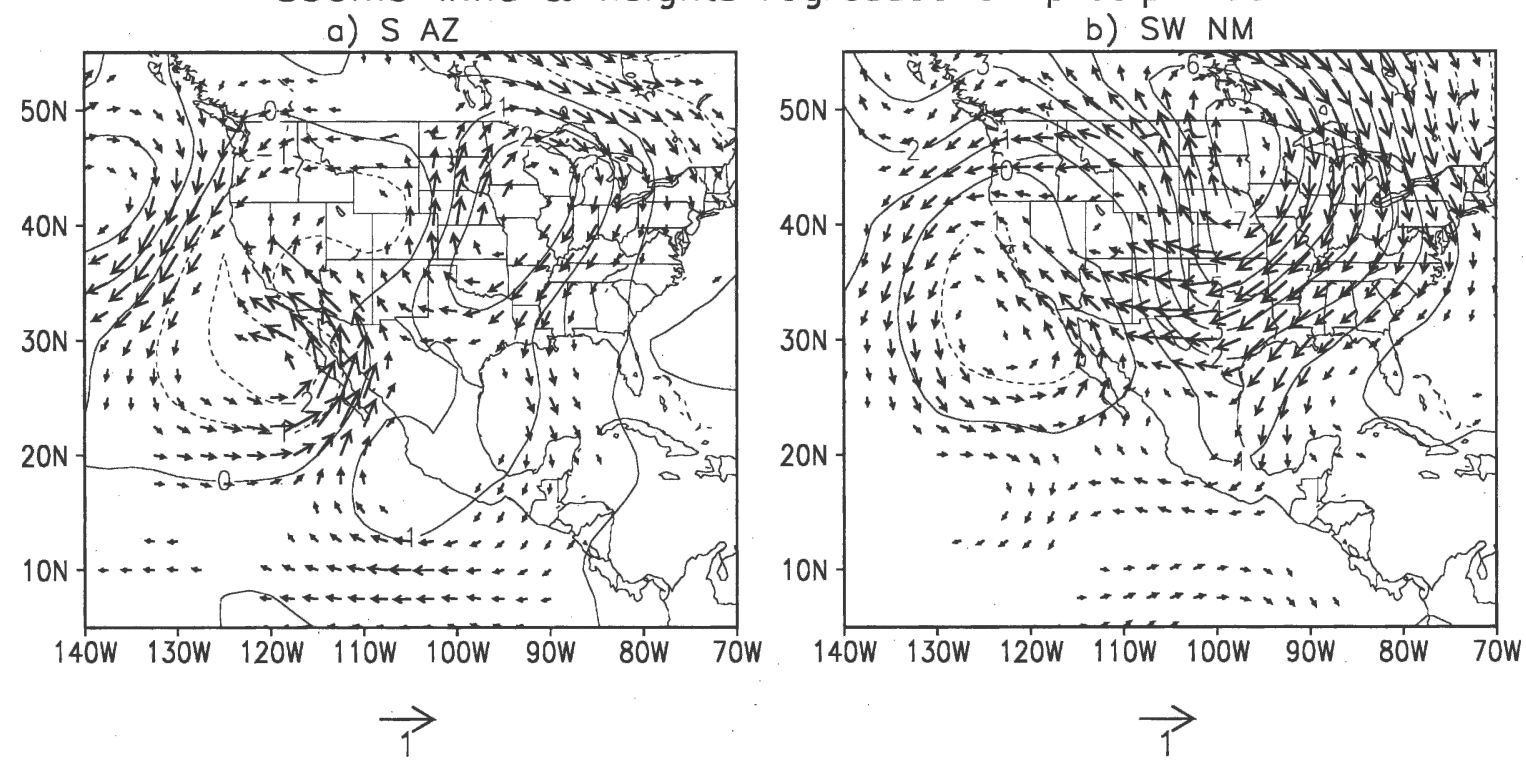

FIG. 5. 850-mb wind (vectors, $\mathrm{m} \mathrm{s}^{-1}$ ) and height (contours, m) anomalies regressed on the (a) SAZ and (b) SWNM precipitation time series (daily data). There is no time lag.

along the Pacific coast in southern Mexico (Higgins and Shi 2001). These precipitation anomalies extend northward to the southern edge of the NAM region. Also note that statistically significant anomalies extend northward into southern Texas at this time. In the U.S. portion of the NAM region, however, the precipitation anomalies are basically zero or perhaps even negative. Three days later $(\mathrm{lag}=1$ triad) the anomalies extend up to the international border, and by nine days later (lag $=3$ triads) the anomalies in southern and central Arizona are among the strongest on the map. An important result evident in Fig. 7 is that the MJO-related precipitation anomalies do not extend into New Mexico yet southwest New Mexico clearly experiences the monsoon-type climate (e.g., Douglas et al. 1993). If the MJO affects the NAM through gulf surges, then this result is consistent with the idea that both the Gulf of California and the Gulf of Mexico are important moisture sources for NAM precipitation (Adams and Comrie 1997). Figure 7 suggests that the degree of influence of gulf surges decreases as one progresses west to east across the NAM region.

\section{d. Mechanism}

This section provides a physical mechanism that might connect zonal wind variability in the tropical $\mathrm{Pa}$ cific with gulf surges over $15^{\circ}$ latitude to the north. As noted in previous studies (Stensrud et al. 1997; Fuller and Stensrud 2000; Douglas and Leal 2003), gulf surges are sometimes associated with the passage of easterly waves over Mexico several days earlier, although the details of how easterly waves trigger a gulf surge are not clear (Stensrud et al. 1997). A time-lagged regression of meridional wind on the SAZ index provides evidence suggesting a connection between SAZ precipitation and easterly waves. Looking at Fig. 8, one can trace meridional wind anomalies at lag $=0$ backward in time to the Caribbean Sea (longitude $<90^{\circ} \mathrm{W}$ ). A similar plot for SWNM does not show a pronounced signal (Fig. 8b).

The connection between NAM precipitation and easterly waves $15^{\circ}$ to the south suggests a possible mechanism whereby MJO variability can effect NAM precipitation. Previous studies have documented the important role of the MJO in modulating easterly waves in the East Pacific (Maloney and Hartmann 2001; Hartmann and Maloney 2001). During the westerly phase of the MJO, the background flow in the East Pacific encourages the amplification of waves off the coast of Mexico. The amplification of these easterly waves off the Mexican coast makes it more likely for the waves to trigger the development of a gulf surge. Figure 9 shows the weekly mean wind anomalies (arrows) as well as the kinetic energy of the deviations from the weekly mean (contours) one week before SAZ precipitation. The anomalous transient kinetic energy preceding SAZ rain is in the same location where 

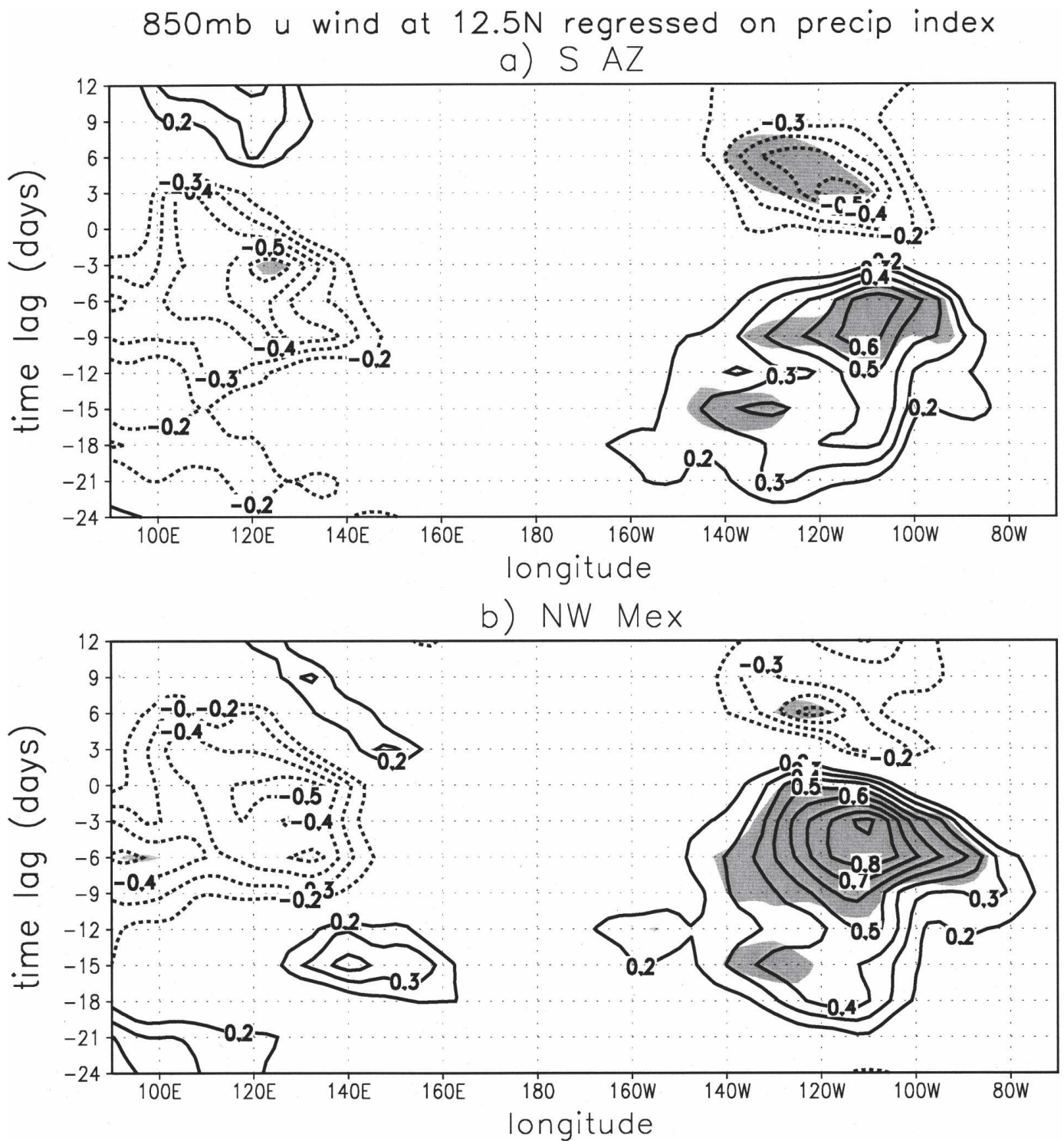

FIG. 6. $850-\mathrm{mb}$ zonal wind anomalies $\left(\mathrm{m} \mathrm{s}^{-1}\right.$ ) along $12.5^{\circ} \mathrm{N}$ regressed on the (a) SAZ and (b) NWMEX precipitation time series for a range of time lags (3-day-mean data). The statistically significant features are shaded $(95 \%)$.

Maloney and Hartmann (2001) find that the flow during the westerly MJO phase is favorable for wave growth (cf. Fig. 9 with their Fig. 7). Thus it appears that the MJO might affect NAM precipitation by amplifying easterly waves in the region critical for triggering the development of a gulf surge.

It is also possible that the MJO affects gulf surges by providing a favorable environment for tropical cyclones, which in turn trigger a gulf surge. Maloney and Hartmann (2000) found that over twice as many named tropical systems (hurricanes and tropical storms) ac- company $850-m b$ westerly anomalies than accompany easterly anomalies, and the systems that do exist are stronger. It is also possible that the westerly MJO events increase monsoon rainfall by providing conditions that lead to favorable cross-orographic flow for the development of mesoscale convective systems in the NAM region.

A summary of the "typical" progression of events in the eastern tropical Pacific that lead to SAZ precipitation is provided below (Fig. 10). Eight days before SAZ precipitation, the most obvious feature is the MJO 


\section{correlation of precip with MJO}

a) time lag $=0$ triads

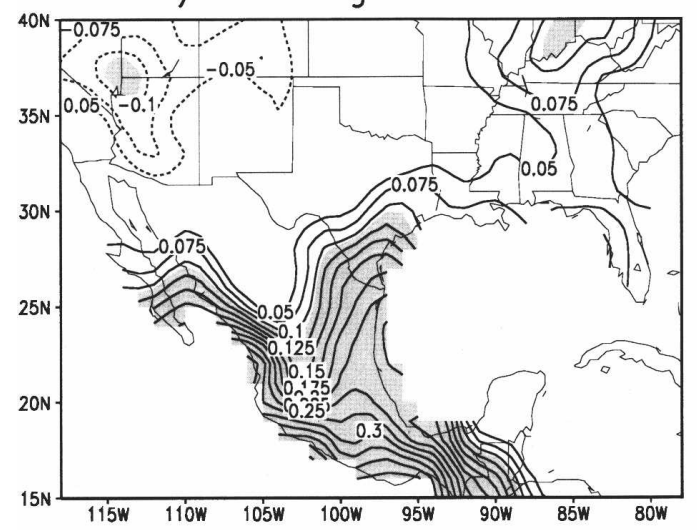

c) time $\operatorname{lag}=+2$ triads

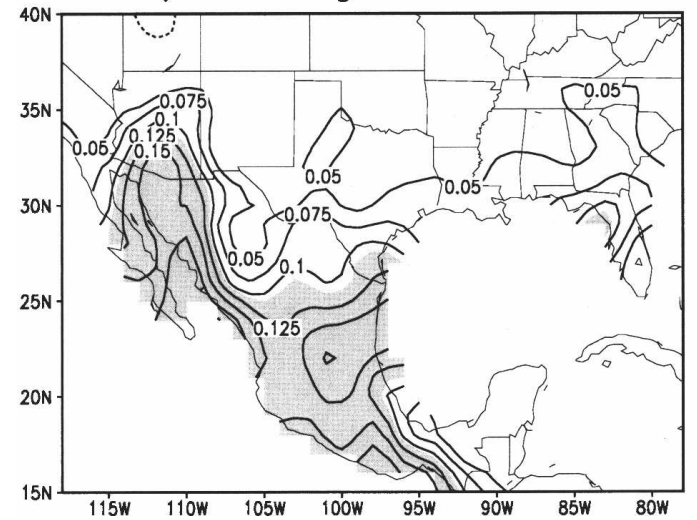

b) time lag $=+1$ triads

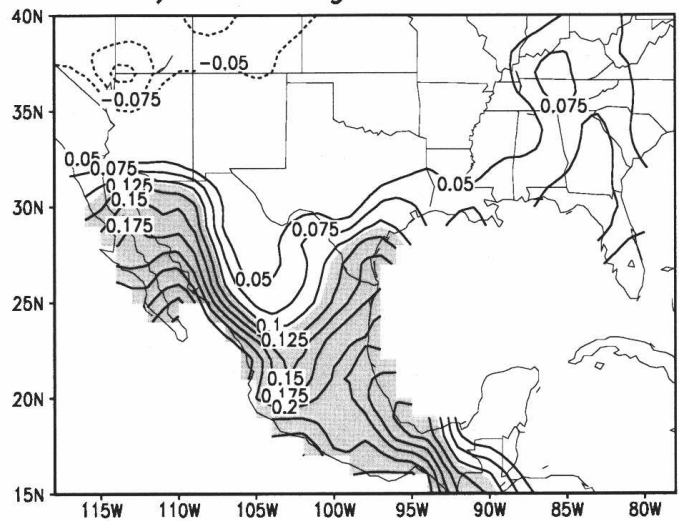

d) time $\log =+3$ triads

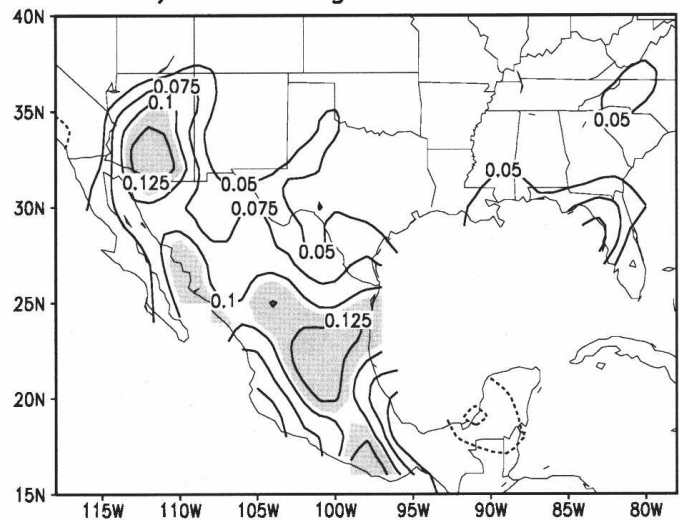

FIG. 7. The correlation between the precipitation anomalies at each grid point and the East Pacific zonal wind index for a range of time lags (3-day-mean data). The statistically significant features are shaded (95\%).

zonal wind pattern at $12.5^{\circ} \mathrm{N}$ (Fig. 10a). In addition, we see southerlies north of Honduras (latitude: $17.5^{\circ} \mathrm{N}$; longitude: $85^{\circ} \mathrm{W}$ ) that are the same as the eastwardpropagating feature evident in Fig. 8a. By lag $=-6$ days, these southerlies have propagated eastward over the Yucatan Peninsula and additional southerlies have begun to appear on the Pacific side of the Mexican highlands. These additional southerlies are part of the cyclonic vortex spinning up on the northern, cyclonic flank of the MJO zonal wind anomalies (Fig. 10b). By lag $=-4$ days, the MJO zonal wind anomalies are significantly weaker than 4 days previous and the cyclonic vortex has grown and moved $2.5^{\circ}$ northward. The growth and movement of the vortex continue at lag $=$ -2 days so that the flow looks very much like a gulf surge at this time. Also note the northerlies north of Honduras, which represent the opposite phase of the subtropical, easterly wave at this location than at lag $=$ -8 days. The lag $=0$ plot is shown in Fig. 5a.
The growth of the "gulf surge vortex" evident in Fig. 10 is clearly not just attributable to the MJO anomalies because there is also the simultaneous development of high heights and associated winds over the U.S. that reinforce the vortex (cf. lag $=-4$ days to lag $=-6$ days). It appears that this high height anomaly over the central plains of the United States is associated with a midlatitude wave train propagating from the Pacific (not shown). Evidently, above-normal AZ rainfall occurs when the midlatitude waves and easterly, subtropical waves are optimally located. The importance of both the midlatitude and the subtropical waves in triggering gulf surges has also been suggested by Stensrud et al. (1997). In addition, recent work (Higgins et al. 2004) has highlighted that the presence of a gulf surge alone is not sufficient to realize above-normal precipitation in Arizona, but that the presence of a strong anticyclonic circulation at middle and upper levels over the central United States is also required. We see the 
$700 \mathrm{mb} v$ wind at $17.5 \mathrm{~N}$ regressed on precip index

a) $\mathrm{S} A Z$

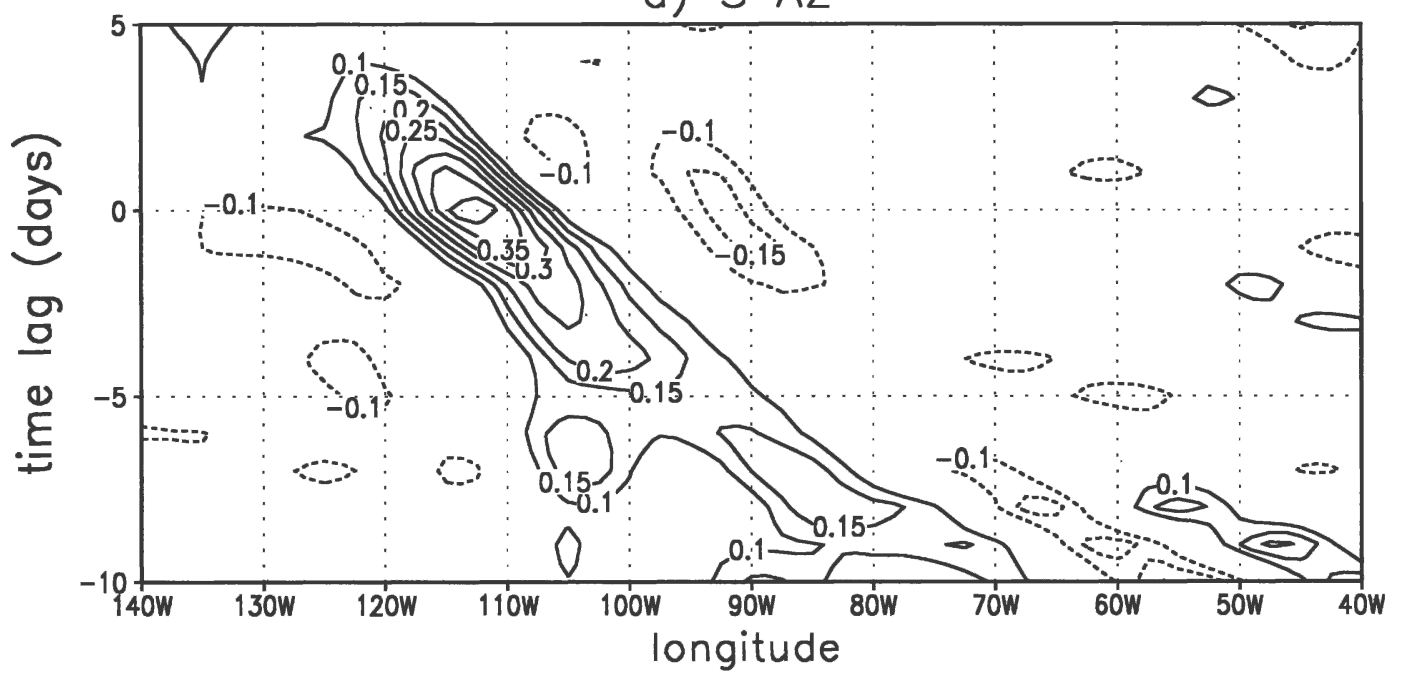

b) SW NM

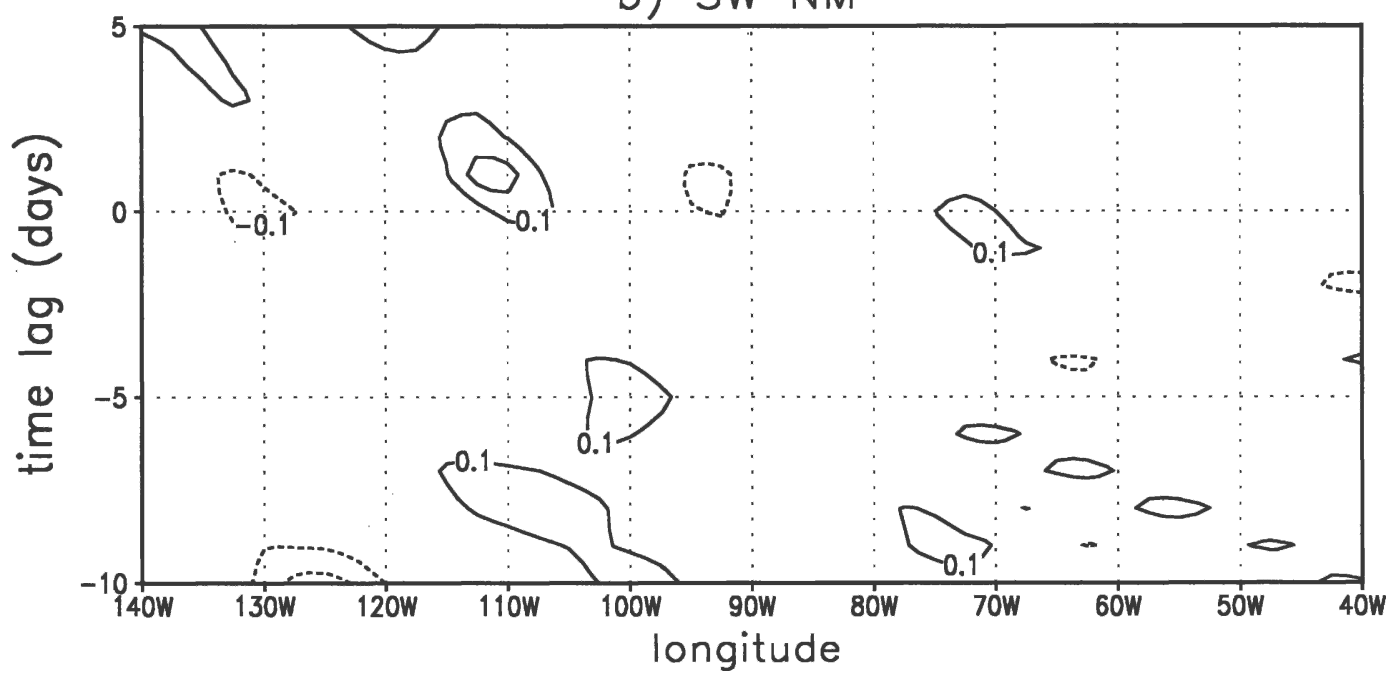

FIG. 8. 700-mb meridional wind anomalies $\left(\mathrm{m} \mathrm{s}^{-1}\right)$ along $17.5^{\circ} \mathrm{N}$ regressed on the (a) SAZ and (b) SWNM precipitation time series for a range of time lags (daily data).

850-mb extension of this anticyclone very clearly in Fig. 10d (cf. our Fig. 10d and Fig. 5a with their Fig. 12a). At middle levels, the winds associated with this anticyclone advect moist air from the southeast over the monsoon region, providing an environment that is favorable for the development of deep convection associated with the gulf surge (Higgins et al. 2004). Thus, it appears that a strong gulf surge (which might have been induced by the MJO) is not sufficient for active monsoon rains but that the middle levels over the monsoon region must also be sufficiently moist for deep convection to develop.

\section{Conclusions}

Zonal wind anomalies in the eastern tropical Pacific associated with the MJO tend to precede above-normal precipitation in the monsoon region of North America from several days to over a week later. The MJO appears to contribute to the development of surges of moisture up the Gulf of California. Thus the time lag between the tropical zonal wind anomalies and monsoon precipitation increases as one moves northward along the gulf of California and into the southwestern United States. A similar connection between the MJO 
tKE regressed on precip (lag $=-1$ week)
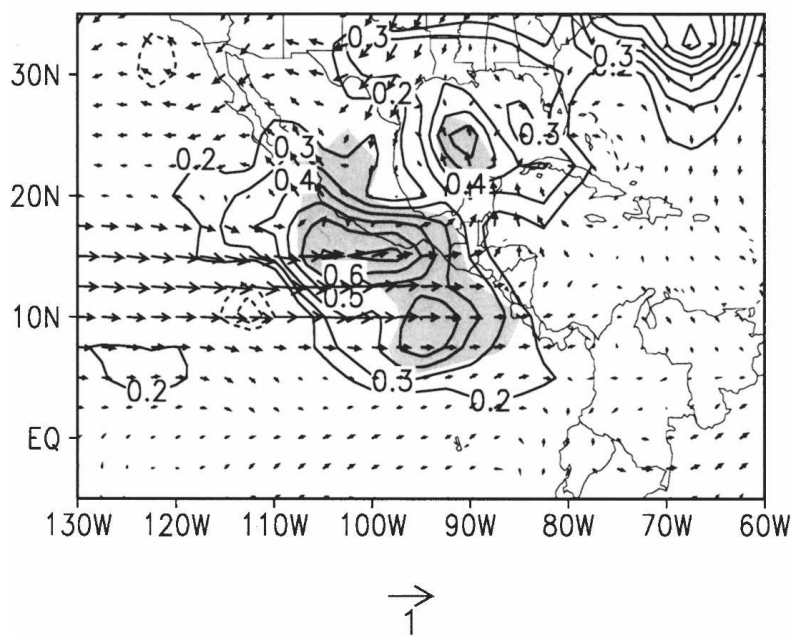

FIG. 9. 850-mb wind anomalies (vectors, $\mathrm{m} \mathrm{s}^{-1}$ ) and transient kinetic energy anomalies (contours, $\mathrm{m}^{2} \mathrm{~s}^{-2}$ ) regressed on the SAZ precipitation time series (weekly mean data). The wind and kinetic energy lead the precipitation by one week. The transients are defined to be the deviation from the weekly mean. and New Mexico precipitation is absent, presumably because New Mexico precipitation is not influenced much by gulf surges.

The mechanism linking the MJO and monsoon precipitation might involve easterly waves propagating into the Pacific from the Caribbean Sea. Previous studies have already documented the important role of easterly waves off the coast of Mexico in triggering a gulf surge (Stensrud et al. 1997; Fuller and Stensrud 2000; Douglas and Leal 2003). The westerly phase of the MJO may increase monsoon precipitation by amplifying easterly waves in the region critical for triggering the development of a gulf surge. An alternative mechanism might involve the effect of the MJO on tropical cyclones in the eastern Pacific (Maloney and Hartmann 2000), which in turn triggers a gulf surge, or perhaps the westerly MJO anomalies eventually lead to favorable cross-orographic flow for mesoscale convective systems.

$850 \mathrm{mb}$ wind \& heights regressed on precip index (S AZ)
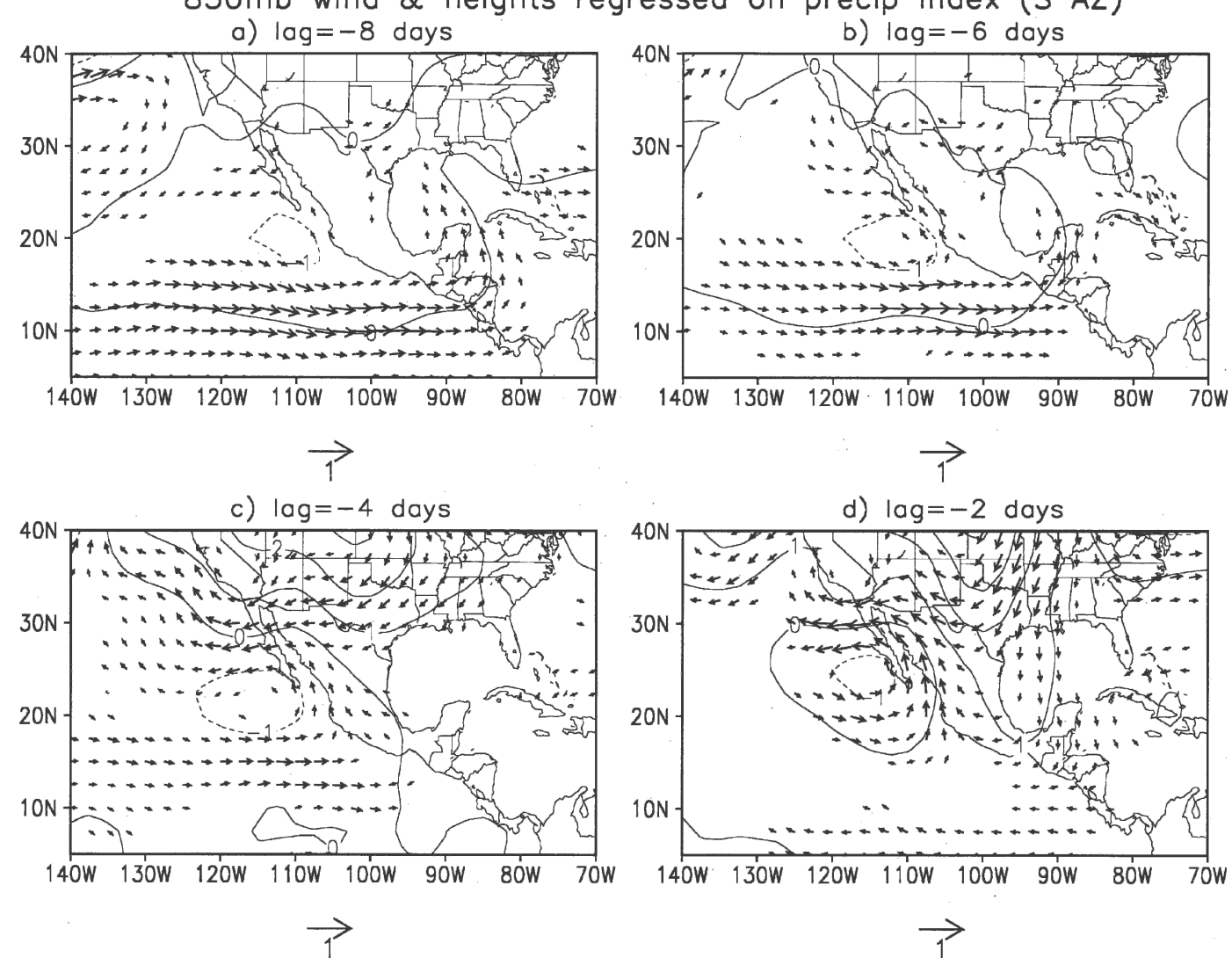

FIG. 10. 850-mb wind (vectors, $\mathrm{m} \mathrm{s}^{-1}$ ) and height (contours, $\mathrm{m}$ ) anomalies regressed on the SAZ precipitation time series for different time lags (daily data). Note that the map scale, vector lengths, and contour interval are the same as in Fig. 5a, which shows the corresponding plot for time lag $=0$ days. 
Acknowledgments. The authors thank the editor, Martin Hoerling, and two anonymous reviewers for their helpful comments and suggestions. This work was supported by NOAA's CLIVAR Pan American Climate Studies (PACS) under Grant GC00-358 and by the Joint Institute for the Study of the Atmosphere and Ocean (JISAO) under NOAA Cooperative Agreement No. NA17RJ1232.

\section{REFERENCES}

Adams, D. K., and A. C. Comrie, 1997: The North American monsoon. Bull. Amer. Meteor. Soc., 78, 2197-2213.

Charba, J. P., A. W. Harrell III, and A. C. Lackner III, 1992: A monthly precipitation amount climatology derived from published atlas maps: Development of a digital database. TDL Office Note 92-7, National Weather Service, NOAA, U.S. Department of Commerce, 20 pp.

Cressman, G. P., 1959: An operational objective analysis system. Mon. Wea. Rev., 87, 367-374.

Douglas, M. W., and J. C. Leal, 2003: Summertime surges over the Gulf of California: Aspects of their climatology, mean structure, and evolution from radiosonde, NCEP reanalysis, and rainfall data. Wea. Forecasting, 18, 55-74.

— R. A. Maddox, K. Howard, and S. Reyes, 1993: The Mexican monsoon. J. Climate, 6, 1665-1677.

Fuller, R. D., and D. J. Stensrud, 2000: The relationship between tropical easterly waves and surges over the Gulf of California during the North American monsoon. Mon. Wea. Rev., 128, 2983-2989.

Glahn, H. R., T. L. Chambers, W. S. Richardson, and H. P. Perrotti, 1985: Objective map analysis for the Local AFOS MOS program. NOAA Tech. Memo. NWS TDL 75, National
Weather Service, NOAA, U.S. Department of Commerce, 34 pp.

Hartmann, D. L., and E. D. Maloney, 2001: The Madden-Julian oscillation, barotropic dynamics, and North Pacific tropical cyclone formation. Part II: Stochastic barotropic modeling. $J$. Atmos. Sci., 58, 2559-2570.

Higgins, R. W., and W. Shi, 2001: Intercomparison of the principal modes of interannual and intraseasonal variability of the North American monsoon system. J. Climate, 14, 403-417.

,$- \ldots$, E. Yarosh, and R. Joyce, 2000: Improved United States Precipitation Quality Control System and Analysis. NCEP/ Climate Prediction Center Atlas No. 7, 40 pp.

- — - and C. Hain, 2004: Relationships between Gulf of California moisture surges and precipitation in the southwestern United States. J. Climate, 17, 2983-2997.

Kalnay, E. M., and Coauthors, 1996: The NCEP/NCAR 40-Year Reanalysis Project. Bull. Amer. Meteor. Soc., 77, 437-471.

Madden, R. A., and P. R. Julian, 1971: Detection of a 40-50 day oscillation in the zonal wind in the tropical Pacific. J. Atmos. Sci., 28, 702-708.

—, and - 1994: Observations of the 40-50 day tropical oscillation-A review. Mon. Wea. Rev., 122, 814-837.

Maloney, E. D., and D. L. Hartmann, 1998: Frictional moisture convergence in a composite life cycle of the Madden-Julian oscillation. J. Climate, 11, 2387-2403.

- , and 2000: Modulation of eastern North Pacific hurricanes by the Madden-Julian oscillation. J. Climate, 13, 14511460 .

— and —, 2001: The Madden-Julian oscillation, barotropic dynamics, and North Pacific tropical cyclone formation. Part I: Observations. J. Atmos. Sci., 58, 2545-2558.

Stensrud, D. J., R. L. Gall, and M. K. Nordquist, 1997: Surges over the Gulf of California during the Mexican monsoon. Mon. Wea. Rev., 125, 417-437. 